\title{
Prevalence and Correlates of Hepatitis C Infection among Male Injection Drug Users in Detention, Tehran, Iran
}

\author{
Parastoo Kheirandish, SeyedAhmad SeyedAlinaghi, \\ MohammadReza Jahani, Hadi Shirzad, \\ MohammadReza Seyed Ahmadian, Ali Majidi, \\ AmirHoushang Sharifi, Mostafa Hosseini, Minoo Mohraz, \\ and Willi McFarland
}

\begin{abstract}
For the benefit of planning for the future care and treatment of people infected with hepatitis $C$ virus (HCV) and to help guide prevention and control programs, data are needed on HCV seroprevalence and associated risk factors. We conducted a cross-sectional sero-behavioral survey of injection drug users (IDU) detained for mandatory rehabilitation during a police sweep of Tehran, Iran, in early 2006. During the study period, a consecutive sample comprising 454 of 499 (91.0\%) men arrested and determined to be IDU by urine test and physical examination consented to a face-to-face interview and blood collection for HCV antibody testing. Overall, HCV prevalence was 80.0\% (95\% confidence interval (CI) 76.2-83.6). Factors independently associated with HCV infection included history of incarceration (adjusted OR 4.35, 95\% CI 1.88-10.08), age of first injection $\leq 25$ years (OR 2.72, 95\% CI 1.09-6.82), and history of tattooing (OR 2.33, 95\% CI 1.05-5.17). HCV prevalence in this population of IDU upon intake to jail was extremely high and possibly approaching saturation. Findings support that incarceration is contributing to the increased spread of HCV infection in Iran and calls for urgent increased availability of HCV treatment, long-term preparation for the care of complications of chronic infection, and rapid scale-up of programs for the primary prevention of parenterally transmitted infections among drug users.
\end{abstract}

KEYWORDS HCV, Prevalence, Risk factors, Injection drug users

\section{INTRODUCTION}

Hepatitis $\mathrm{C}$ virus (HCV) infection is increasingly recognized as a major healthcare problem throughout the world. The World Health Organization estimates 170 million people to be infected worldwide. Almost $85 \%$ of cases can become

Kheirandish, SeyedAlinaghi, Sharifi, and Mohraz are with the Iranian Research Center for HIV/AIDS (IRCHA), Department of Infectious and Tropical Diseases, Tehran University of Medical Sciences, Tehran, Iran; Jahani is with the Department of Medicine, Baghiyat-Allah University, Tehran, Iran; Shirzad and Seyed Ahmadian are with the Research Center-Headquarter of Police Force Medicine, Tehran, Iran; Majidi is with the Headquarter of Police Force Medicine, Tehran, Iran; Hosseini is with the Department of Epidemiology \& Biostatistics, School of Public Health, Tehran University of Medical Sciences, Tehran, Iran; McFarland is with the CAPS and the Institute for Global Health, University of California, San Francisco, CA, USA.

Correspondence: Mostafa Hosseini, PhD, Department of Epidemiology \& Biostatistics, School of Public Health, Tehran University of Medical Sciences, Tehran, Iran. (E-mail: Mhossein110@yahoo.com) 
chronic and experience serious long-term complications, such as hepatic cirrhosis or carcinoma. Patients can remain symptom-free for a long time; for example, liver disease may appear up to 20 or 30 years after the initial infection. ${ }^{1-4}$

$\mathrm{HCV}$ infection is recognized as the most common blood-borne infection in injection drug users (IDU). HCV prevalence can reach $30 \%$ to $60 \%{ }^{5-7}$ within a few years of its first appearance in a population of IDU and achieve greater than $90 \%$ in a mature epidemic. ${ }^{8}$ The main mode of HCV transmission among IDU is by sharing injection equipment not limited to needle sharing alone. ${ }^{9}$ Since prisons contain a high proportion of IDU, HCV is usually more prevalent in incarcerated populations than in the surrounding community. ${ }^{5,6}$ In addition, prisons may foster further spread of HCV due to injection within jail, increased sharing due to scarcity of clean injection equipment, and the high prevalence of the virus among co-inmates. ${ }^{10,11}$ Tattooing, a common practice in jails, is also an identified risk factor for HCV infection. ${ }^{12}$ Iran has started a number of harm reduction programs for tackling the HIV, HBV, and HCV epidemic among IDUs. Methadone maintenance therapy and needle-exchange programs have been established in many prisons. Likewise, condom distribution exists, but it should be expanded. There are more than 60 triangular clinics (sexually transmitted infections, HIV/AIDS, drug abuse) across Iran, but it is unclear how many of these have initiated needle-exchange programs. ${ }^{13,14}$

Knowledge of the prevalence and risk factors of HCV infection is essential for short- and long-term public-health responses to prevent, control, treat, and mitigate the impact of this increasingly common and serious infection. We, therefore, assessed the prevalence of HCV infection and associated risk behaviors among IDU upon intake to detention in Tehran, Iran.

\section{METHODS}

We conducted a cross-sectional survey of male IDU consecutively recruited upon detention in Tehran, Iran, to measure the prevalence of HCV and associated risk factors for infection. Police conducted a "sweep" of IDU in early 2006 at check points in Tehran neighborhoods with high incidence of drug-related arrests and petty crime. Men loitering in the areas were intercepted by police using a drug user "profile" of demographic characteristics and appearance. Men suspected of drug use after questioning were sent to a temporary detention center. They were then screened for drugs using a urine test and physically examined for injection marks by an experienced drug-addiction physician. Those who were identified by urine screen and exam as IDU were sent to a mandatory drug rehabilitation center for 12 weeks.

We consecutively offered detainees participation in our study upon arrival at the mandatory rehabilitation center. After providing consent, a face-to-face structured interview was conducted by a physician and included demographic information, imprisonment history, and injecting practices ever in the past and during previous incarcerations. Blood specimens were collected by a professional phlebotomist and tested for HCV antibody by EIA (DiaSorin, Spain). Non-identifying codes were used to record all data and to link laboratory test results to the questionnaires. Data were analyzed using STATA (8.0). HCV point prevalence was calculated as the number of $\mathrm{HCV}$-positive individuals divided by the number of test results overall and stratified by demographic characteristics, incarceration history, and drug-use practices. "Decline to answer" and missing data for many questions were coded as 1 = acknowledging behavior and $0=$ not acknowledging behavior. 
Multiple logistic regression analysis was used to determine associations with HCV infection. Variables associated with HCV in bivariate analysis at the $p \leq 0.10$ level were included as potential independent predictors. The final model retained those variables associated with infection at the $p<0.05$ level.

No special privileges, money, or other incentives were given, and participation was voluntary. Strict confidentiality of data including laboratory results was maintained with no results or other information released to the jail health or justice/prison system. Referrals to care were made to the Tehran University Medical School. The institutional review board of Tehran University of Medical Sciences approved the study protocol.

\section{RESULTS}

The police detained a total of 499 male IDU during 12 weeks. Of these, $454(91.0 \%)$ consented to participate in the survey and were tested for HCV antibodies. The majority $(65.6 \%)$ were under 35 years old, were or had been married $(39.6 \%$ currently married, $21.7 \%$ divorced, $0.7 \%$ widowed), and did not complete high school $(81.1 \%)$.

Overall HCV prevalence was $80.0 \%$ (95\% confidence interval (CI) 76.2-83.6; Table 1). When asked about prior testing for HCV, $37.7 \%$ reported that they were tested and knew their previous result. Of these subjects, 96.7\% stated they had HCV infection (data not shown). There was a significant association between age and $\mathrm{HCV}(p=0.04)$, with prevalence already high at $67.2 \%$ among 17 - to 24 -year-olds and increasing to $87.7 \%$ among those 45 years and older. Although years of drug use was not associated with HCV infection, time engaging in injection achieved over 95\% prevalence after 5 years. Moreover, there was a borderline association between HCV infection and younger age of first injection. Elevated HCV prevalence was significantly associated with reporting ever sharing injection equipment, history of tattooing, and history of prior incarceration. No associations with HCV infection were found with respect to marital status, Tehran residence, education level, or types of drugs used. While history of prior incarceration was associated with HCV infection (reported by $75.3 \%$ ), we detected no associations with specific reported behaviors while in jail (Table 2).

Entering all variables associated with HCV infection at the $p \leq 0.10$ level into a multiple regression model and retaining those significantly associated at $p<0.05$ identified three independent predictors: history of prior incarceration (adjusted odds ratio (AOR) 4.35, 95\% CI 1.88-10.08), age of first injection by 25 years of age (AOR $2.72,95 \%$ CI 1.09-6.82), and history of tattooing (AOR 2.33, 95\% CI 1.05-5.17).

\section{DISCUSSION}

HCV infection in our consecutive sample of IDU on entry into detention was astonishingly high: four-fifths were infected overall; nearly $90 \%$ were infected by age 45 years and over $95 \%$ after 5 years of injection. Our estimates are among the highest in the world and, to our knowledge, the highest recorded in Iran to date. $^{15-18}$ For example, in the late 1990 s, HCV prevalence among drug-using prisoners in Hammadan, Iran, was $7.3 \%$ with higher prevalence among IDU. ${ }^{17}$ In 2001 in Zanjan, Iran, HCV prevalence was measured at $47.7 \%$ among 346 drugaddict prisoners. ${ }^{18} \mathrm{HCV}$ prevalence was measured at $60 \%$ among incarcerated IDU in Mashhad, Iran, 4 years earlier than our survey. ${ }^{16}$ These studies point to a 
TABLE 1 Characteristics, behaviors, and HCV seroprevalence among injection drug users upon detention, Tehran, Iran, 2006

\begin{tabular}{|c|c|c|c|}
\hline & $N^{a}$ & $\mathrm{HCV}+$ & HCV seroprevalence $\%$ \\
\hline Variable & (\%) & $(N)$ & $(95 \% \mathrm{Cl})$ \\
\hline Total & $454(100)$ & 363 & $80.0(76.2-83.6)$ \\
\hline \multicolumn{4}{|l|}{ Age group* } \\
\hline $17-24$ years & $61(13.8)$ & 41 & $67.2(54.0-78.7)$ \\
\hline $25-34$ years & $229(51.8)$ & 185 & $80.8(75.1-85.7)$ \\
\hline $35-44$ years & $103(23.3)$ & 85 & $82.5(73.8-89.3)$ \\
\hline$\geq 45$ years & 49 (11.1) & 43 & $87.7(75.2-95.4)$ \\
\hline \multicolumn{4}{|l|}{ Marital status } \\
\hline Single & $168(38.0)$ & 133 & $79.2(72.2-85.0)$ \\
\hline Married & $175(39.6)$ & 141 & $80.6(73.9-86.1)$ \\
\hline Divorced & $96(21.7)$ & 77 & $80.2(70.8-87.6)$ \\
\hline Widowed & $3(0.7)$ & 3 & $100.0(29.2-100.0)^{b}$ \\
\hline \multicolumn{4}{|l|}{ Residence } \\
\hline Outside of Tehran & $71(16.2)$ & 60 & $84.5(74.0-92.0)$ \\
\hline Tehran & $367(83.8)$ & 292 & $79.6(75.1-83.6)$ \\
\hline \multicolumn{4}{|l|}{ Education level: } \\
\hline & $30(6.8)$ & 23 & $76.7(57.7-90.1)$ \\
\hline Did not complete high school & $326(74.3)$ & 265 & $81.3(76.6-85.4)$ \\
\hline Completed high school or higher & $83(18.9)$ & 63 & $75.9(66.3-84.6)$ \\
\hline \multicolumn{4}{|l|}{ Drugs reported ever used (local name) } \\
\hline Opium (taryak) & $360(79.3)$ & 287 & $79.7(75.2-83.7)$ \\
\hline Boiled opium resin (shireh) & $100(22.0)$ & 83 & $83.0(74.2-89.8)$ \\
\hline Opium resin (sookteh) & $82(18.1)$ & 68 & $82.9(73.0-90.3)$ \\
\hline Heroin & $334(73.6)$ & 273 & $81.7(77.2-85.7)$ \\
\hline "Crack" (purer form of heroin) & $71(15.6)$ & 52 & $73.2(61.4-83.1)$ \\
\hline Hashish & $131(28.9)$ & 102 & $77.9(69.8-84.6)$ \\
\hline Bupenorphine (norgeezak) & $436(96.0)$ & 346 & $79.4(75.2-83.1)$ \\
\hline Bupenorphine + steroids (afzoor) & $9(2.0)$ & 8 & $88.9(51.7-99.7)$ \\
\hline Methamphetamine (crystal) & $18(4.0)$ & 12 & $66.7(41.0-86.7)$ \\
\hline Morphine & $11(2.4)$ & 7 & $63.6(30.8-89.1)$ \\
\hline Other drug & $59(13.0)$ & 47 & $79.7(67.2-89.0)$ \\
\hline \multicolumn{4}{|l|}{ Years of drug use } \\
\hline Up to 1 year & $26(11.7)$ & 21 & $80.8(60.6-93.4)$ \\
\hline 2 to 5 years & $69(30.9)$ & 56 & $81.2(69.9-89.6)$ \\
\hline More than 5 years & $128(57.4)$ & 108 & $84.4(78.0-90.7)$ \\
\hline \multicolumn{4}{|l|}{ Years of injection** } \\
\hline Up to 1 year & $77(39.5)$ & 55 & $71.4(60.0-81.1)$ \\
\hline 2 to 5 years & $72(36.9)$ & 62 & $86.1(75.9-93.1)$ \\
\hline More than 5 years & $46(23.6)$ & 44 & $95.6(85.2-99.5)$ \\
\hline Age of first injection $\leq 25$ years old $* * *$ & $73(37.4)$ & 65 & $89.0(79.5-95.1)$ \\
\hline Reported ever sharing needles & $58(12.8)$ & 49 & $84.5(72.6-92.6)$ \\
\hline Reported ever sharing injection equipment* & $119(26.2)$ & 104 & $87.4(80.1-92.8)$ \\
\hline Reported ever sharing needles or equipment* & $123(27.1)$ & 106 & $86.2(78.8-91.7)$ \\
\hline Reported past history of incarceration $* * * * *$ & $342(75.3)$ & 285 & $83.3(79.0-87.1)$ \\
\hline Reported history of using an opioid in jail & $85(18.7)$ & 73 & $85.9(76.6-92.5)$ \\
\hline Reported history of injection in jail & $30(6.6)$ & 27 & $90.0(73.5-97.9)$ \\
\hline History of using shared materials in jail & $28(6.2)$ & 25 & $89.3(71.8-97.7)$ \\
\hline History of using sharp objects in jail & $112(24.7)$ & 95 & $84.8(76.8-90.9)$ \\
\hline Reported past access to new syringes in jail & $313(68.9)$ & 246 & $78.6(73.6-83.0)$ \\
\hline History of tattooing**** & $125(27.5)$ & 111 & $66.7(41.0-86.7)$ \\
\hline
\end{tabular}

\footnotetext{
${ }^{\text {a}}$ Subgroups do not always add up to total due to missing data

${ }^{\mathrm{b}}$ One-sided $97.5 \% \mathrm{Cl}$

${ }^{*} p \leq 0.05,{ }^{* *} p \leq 0.001,{ }^{* * *} p \leq 0.10, * * * * p \leq 0.01$
} 
TABLE 2 Independent associations of HCV infection among injection drug users upon detention, Tehran, Iran, 2006

\begin{tabular}{lcc}
\hline Model & Adjusted OR $(95 \% \mathrm{Cl})$ & $P$ value \\
\hline History of prior incarceration & $4.35(1.88-10.08)$ & 0.001 \\
Age of first injection $\leq 25$ years old & $2.72(1.09-6.82)$ & 0.032 \\
History of tattooing & $2.33(1.05-5.17)$ & 0.037 \\
\hline
\end{tabular}

relentless increase in HCV over the last decade, culminating in saturation with our current study. ${ }^{8}$

Not only do our data speak to a catastrophic future burden of disease and health care need due to HCV but they also serve as an indicator of the potential spread of HIV. Both infections have similar routes of transmission through injection practices, but because $\mathrm{HCV}$ is more infectious, it acts as a biological marker or herald for future HIV transmission. Given the near saturation of HCV infection in our study after a few years of injection, HIV infection may already be at a peak among IDU in Iran-and especially among IDU with exposure to incarceration.

Our study corroborates the potential role that incarceration plays in propagating HCV, with prior history of incarceration imparting a fourfold increased risk. This result is consistent with multiple studies around the world that also find incarceration associated with HCV infection and with the injection-related practices that lead to HCV infection. ${ }^{16-24}$ In addition, it is possible for non-injection drug users to be at elevated risk for HCV due to incarceration, ${ }^{19,25,26}$ either through modes of transmission other than sharing injection equipment or because persons smoking opium may resort to injection while in jail due to the scarcity of raw opium and the inability to hide smoking. Of note, our data show that opium use is quite high among this population. Moreover, Iran has one of the highest per capita rates of opioid use in the world. ${ }^{18}$ Thus, in the Iranian context, incarceration of drug users may be particularly detrimental to controlling the spread of HCV. We also found that history of tattooing, a practice also common to incarcerated populations, was an independent risk factor for HCV infection. ${ }^{18,27-29}$ In the abovementioned study of prisoners in Zanjan, tattooing was also associated with HCV positivity among prisoners. ${ }^{18}$

Of note, we did not find a direct association between HCV and the reporting of specific practices while in jail, only the global indicator of past incarceration. This may be due to bias in underreporting of illegal behaviors while in the jail setting. Other limitations of this study include the mismatch between recall time period and potential exposure, the reliability of other responses in the jail setting, and the representativeness of the sample to all IDU. Also, there was no confirmatory test for HCV. We believe, however, that these factors are not likely to change the conclusion of high HCV prevalence among IDU in Tehran.

The extremely high rate of $\mathrm{HCV}$ in this population presents dismaying challenges for Iran. Programs for the future care of HCV-infected persons will need to be scaled up rapidly. One front to address is the timely screening of persons at risk, the early identification of persons infected, and the provision of effective treatment, hopefully to bring about cure. These measures are relatively expensive and currently not widely available in Iran. We hope our data will help advocate for expanding the opportunities for the diagnosis and treatment of HCV. The jail system, through which many drug-users pass, is one point to enhance HCV 
programs. Drug-treatment programs are another. The healthcare system of Iran will also have to prepare itself for the long-term consequences of HCV infection, including liver carcinoma and failure. Primary prevention may be even more challenging, not least because the prevalence of infection is already so high. Nonetheless, there will likely be future generations of as yet uninfected young drug users for whom increased harm-reduction programs, including needle exchange and methadone maintenance, will be needed to avert further disaster.

\section{ACKNOWLEDGEMENTS}

This research has been supported by Tehran University of Medical Sciences and Health Services grant and Darioush Research Institute (grant number 801/86/7056).

Conflicts of interest. No conflict exists

OPEN ACCESS This article is distributed under the terms of the Creative Commons Attribution Noncommercial License which permits any noncommercial use, distribution, and reproduction in any medium, provided the original author(s) and source are credited.

\section{REFERENCES}

1. Adjei AA, Armah HB, Gbagbo F, et al. Correlates of hepatitis C virus infection among incarcerated Ghanaians: a national multicentre study. J Med Microbiol. 2007; 56: 391-397.

2. Lauer GM, Walker BD. Hepatitis C virus infection. N Engl J Med. 2001; 345: 41-52.

3. Van Asten L, Verhaest I, Lamzira S, et al. Spread of hepatitis C virus among European injection drug users infected with HIV: a phylogenetic analysis. J Infect Dis. 2004; 189: 292-302.

4. McCarthy JJ, Flynn N. Hepatitis C in methadone maintenance patients: prevalence and public policy implications. J Addict Dis. 2001; 20: 19-31.

5. Shafer KP, Hahn JA, Lum PJ, et al. Prevalence and correlates of HIV infection among young injection drug users in San Francisco. JAIDS. 2002; 31: 422-431.

6. Monga HK, Rodrguez-Barradas MC, Breaux K, et al. Hepatitis $\mathrm{C}$ virus infection-related morbidity and mortality among patients with human immunodeficiency virus infection. Clin Infect Dis. 2001; 33: 240-247.

7. European Monitoring Centre for Drugs and Drug Addiction. Annual report on the state of the drugs problem in the European Union. 2003. Luxembourg: Office for Official Publications of the European Communities, 2003.

8. Falstar K, Kaldor JM, Maher L, for the collaboration of Australian Needle and Syringe Programs. Hepatitis C acquisition among injection drug users: a cohort analysis of a national repeated cross-sectional survey of needle and syringe program attendees in Australia, 1995-2004. J Urban Health 2008; epub ahead of print.

9. Taylor A, Goldberg D, Hutchinson S, et al. High risk injecting behavior among injectors from Glasgow: cross sectional community wide surveys 1990-1999. J Epidemiol Community Health. 2001; 55: 766-767.

10. Stover H, Nelles J. Ten years of experience with needle and syringe exchange programmes in European prisons. Int J Drug Policy. 2003; 14: 437-444.

11. Romero M, Oviedo-Joekes E, Mach Cerda JC, et al. Programa de Jeringuillas. Adicciones. 2005; 17: 257-275. 
12. Adjei AA, Armah HB, Gbagbo F, et al. Prevalence of human immunodeficiency virus, hepatitis $B$ virus, hepatitis $C$ virus and syphilis among prison inmates and officers at Nsawam and Accra, Ghana. J Med Microbiol. 2006; 55: 593-597.

13. Nassirimanesh B, Trace M, Roberts $M$. The rise of harm reduction in the Islamic Republic of Iran. Briefing Paper Eight, The Beckley Foundation Drug Policy Programme, 2005.

14. Eshrati B, Taghizadeh Asl R, Anne Dell C, et al. Preventing HIV transmission among Iranian prisoners: initial support for providing education on the benefits of harm reduction practices. Harm Reduct. 2008; 5: 21.

15. Shirin T, Ahmed T, Iqbal A, et al. Prevalence and risk factor of hepatitis B virus, hepatitis $\mathrm{C}$ virus, and human immunodeficiency virus infections among drug addicts in Bangladesh. J Health Popul Nutr. 2000; 18: 145-150.

16. Rowhani Rahbar A, Rooholamini S, Khoshnood K. Prevalence of HIV infection and other blood-borne infections in incarcerated and non-incarcerated injection drug users (IDUS) in Mashhad, Iran. International Journal of Drug Policy. 2004; 15: 151-155.

17. Mohammad Ali Zadeh AH, Alavian SM, Jafari K, et al. Prevalence of HBS AG, HC AB \& HIV AB in the addict prisoners of Hammadan prison (Iran, 1998). Journal of Research in Medical Sciences. 2003; 7: 311-313.

18. Khani M, Vakili MM. Prevalence and risk factors of HIV, hepatitis B virus and hepatitis C virus infections in drug addicts among Zanjan prisoners. Arch Iranian Med. 2003; 6: 1-4.

19. Day C, Nassirimanesh B, Shakeshaft A, et al. Patterns of drug use among a sample of drug users and injecting drug users attending a General Practice in Iran. Harm Reduct J. 2006; 3: 2.

20. Christensen PB, Kraup HB, Nietters HG, et al. Prevalence and incidence of blood borne viral infections among Danish prisoners. Eur J Epidemiol. 2001; 16: 1043-1049.

21. Fox RK, Currie SL, Jennifer Evans J, et al. Hepatitis C virus infection among prisoners in the california state correctional system. Clin Infect Dis. 2005; 41: 177-186.

22. March JC, Oviedo-Joekes E, Romero M. Factors associated with reported hepatitis C and HIV among injecting drug users in ten European cities. Enferm Infecc Microbiol Clin. 2007; 25: 91-97.

23. Stark K, Bienzle U, Vonk R, et al. History of syringe sharing in prison and risk of hepatitis $\mathrm{B}$ virus, hepatitis $\mathrm{C}$ virus, and human immunodeficiency virus infection among injecting drug users in Berlin. Int J Epidemiol. 1997; 26: 1359-1366.

24. Quaglio G, Lugoboni F, Pajusco B, et al. Factors associated with hepatitis C virus infection in injection and noninjection drug users in Italy. Clin Infect Dis. 2003; 37: 3340.

25. Centers for Disease Control and Prevention. Recommendations for prevention and control of hepatitis C virus (HCV) infection and HCV-related chronic disease. MMWR Recomm Rep. 1998; 47(RR-19): 1-39.

26. National Institutes of Health. National Institutes of Health consensus development conference statement: management of hepatitis C, 2002. Available at: http://www. consensus.nih.gov/cons/116/091202116cdc_statement.htm. Accessed 31 January 2005.

27. Samuel MC, Doherty PM, Bulterys M, et al. Association between heroin use, needle sharing and tattoos received in prison with hepatitis $\mathrm{B}$ and $\mathrm{C}$ positivity among streetrecruited injecting drug users in New Mexico, USA. Epidemiol infect. 2001; 127: 475484.

28. Skoretz S, Zaniewski G, Goedhuis NJ. Hepatitis C virus transmission in the prison/inmate population. Can Commun Dis Report. 2004; 30: 16-26.

29. Babudieri S, Longo B, Sarmati L, et al. Correlates of HIV, HBV, and HCV infections in a prison inmate population: results from a multicentre study in Italy. J Med Virol. 2005; 76: 311-317. 